\section{Mena, a new available marker in tumors of salivary glands?}

\author{
S. Gurzu, ${ }^{1}$ M. Krause, ${ }^{2}$ I. Ember, ${ }^{3}$ \\ L. Azamfirei, ${ }^{4}$ G. Gobel, ${ }^{3}$ K. Feher, ${ }^{3}$ \\ I. Jung' \\ 'Department of Pathology, University \\ of Medicine and Pharmacy of \\ Targu-Mures, Romania \\ 2Randall Division of Cell \& Molecular \\ Biophysics, King's College London, UK \\ ${ }^{3}$ Department of Public Health, University \\ of Pécs, Hungary \\ ${ }^{4}$ Department of Intensive Care, \\ University of Medicine and Pharmacy of \\ Targu-Mures, Romania
}

\section{Abstract}

Mena (mammalian Ena) is an actin regulatory protein involved in cell motility and adhesion. Based on its potential role in malignant transformation revealed in other organs, we analyzed the Mena expression in normal salivary glands (SG) and salivary tumors. Mena expression was determined in normal SG $(n=10)$ and also benign $(n=20)$ and malignant $(n=35)$ lesions of SG. For the immunohistochemical staining we used the anti-Mena antibody. All normal SG and the benign lesions (10 pleomorphic adenomas, 10 Warthin's tumors) were Mena negative. Salivary duct carcinomas $(n=5)$, carcinomas in pleomorphic adenoma $(n=5)$, acinic cell carcinomas $(n=5)$, squamous cell carcinomas $(n=10)$ and high-grade mucoepidermoid carcinomas $(n=2)$ were positive. The lymphomas $(n=5)$ and low-grade mucoepidermoid carcinomas $(\mathrm{n}=1)$ were Mena negative. In one case the lymphoblastic cells stained positive for Mena. Some of the endothelial cells, in the peritumoral vessels, were Mena positive. To the best of our knowledge, this is the first study in the literature about Mena expression in salivary tumors. Our study suggests that Mena protein seems to play a role in malignant transformation and its intensity is correlated with the type and grade of tumor and also with vascular invasion. Its positivity in endothelial cells may suggest its potential role in tumor angiogenesis.

\section{Introduction}

Carcinomas of salivary gland (SG) represent $3-5 \%$ of head and neck tumors ${ }^{1}$ respectively $11 \%$ of all oropharyngeal neoplasms. ${ }^{2}$ Half of salivary gland tumors are pleomorphic adeno- mas. ${ }^{3}$ Malignant tumors are relatively rare. Some of them are developing in pleomorphic adenomas but the pathomechanism of carcinogenesis and prognostic factors of these cases are still under debate. However, lymph node metastases and relapses have been reported and therefore the outcome is not always favorable. The causes of relapses have been attributed to the positivity of resection margins, or unfavorable prognostic factors such as tumor stage, gender, age, histological grade, site and size of tumor as well as status of regional lymph nodes. ${ }^{4}$

Based on the tumor agresitivity and histological aspect, malignant tumors of salivary glands are classified in low grade (low-grade adenocarcinoma, basal cell adenocarcinoma, acinic cell carcinoma, clear cell adenocarcinoma, epithelial-myoepithelial carcinoma, and cystadenocarcinoma) and high grade (salivary duct carcinoma, squamous cell carcinoma, adenosquamous carcinoma, oncocytic carcinoma, sebaceous carcinoma and undifferentiated carcinomas) but in some tumors (mucoepidermoid carcinoma, adenocarcinoma NOS, adenoid cystic carcinoma and malignant mixed tumors) the grading system is still under debate. ${ }^{5}$ New markers and molecular analyses are necessary to be introduced in these cases in the daily diagnosis in order to predict prognosis and capacity of metastasing. ${ }^{5}$

Recent studies proved that cell migration and adhesion is mediated by the actin cytoskeleton and altered expression of regulators of the actin cytoskeletal network can contribute to metastasis. ${ }^{6}$ One protein family regulating actin cytoskeleton dynamics is the enabled/vasodilator stimulated phosphoprotein (Ena/NASP) family. ${ }^{7}$ Members of this family in vertebrates are Mena (mammalian Ena), VASP (vasodilator stimulated phosphoprotein) and EVL (Ena/VASP-like). Ena/VASP proteins play a crucial role in cell motility by antagonizing actin filament capping.

In breast and pancreatic carcinomas and also in melanomas it was observed that Mena was up-regulated and facilitated metastasis. ${ }^{8,9}$ There are previously reported that Mena expression is up-regulated during malignant transformation of colorectal tumors and cervical intraepithelial into invasive neoplasia. ${ }^{10,11}$ However, expression levels of Mena during carcinogenesis of salivary glands have not yet been reported.

Therefore, we have analysed Mena expression levels in normal salivary glands and in some of the benign and malignant salivary tumors in order to determine its potential role as biomarker for tumor progression.
Correspondence: Prof. Azamfirei Leonard, Department of Intensive Care, University of Medicine and Pharmacy, 38 Ghe Marinescu Street, 540139, Targu Mures, Romania.

Tel. + 40.74.4828224.

E-mail: simonagurzu@yahoo.com

Key words: salivary glands, Mena protein, carcinomas, lymphomas.

Acknowledgements: this paper is partially supported by the project PNII-PD 504/2010 - CNCSISUEFISCSU, Romania, the Sectoral Operational Programme Human Resources Development, financed from the European Social Fund and by the Romanian Government under the contract number POSDRU/89/1.5/S/60782 and by the project PNII-IDEI code 136/2008.

Received for publication: 5 November 2011. Accepted for publication: 13 January 2012.

This work is licensed under a Creative Commons Attribution NonCommercial 3.0 License (CC BYNC 3.0).

○C Copyright S. Gurzu et al., 2012

Licensee PAGEPress, Italy

European Journal of Histochemistry 2012; 56:e8 doi:10.4081/ejh.2012.e8

\section{Materials and Methods}

Paraffin embedded tissues of 65 patients with normal salivary glands and primary salivary gland tumors diagnosed in Department of Pathology of Emergency Hospital of TarguMures, Romania, during 2005-2011 were retrospectively analysed. The selection process included a randomized selection depending on the diagnosis time. Due to small number of cases no other criterias have been used. Protein expression levels were correlated with demographic data and clinical outcome including relapses. Ethical committee of our University granted their approval for these techniques. Written informed consent from patients was obtained for this study. Number of tumors and normal tissue with SG are shown in Table 1.

For immunohistochemical staining we used the monoclonal anti-Mena antibody, isotype mouse IgA, clone 21 (BD Biosciences, Sparks, MD, USA) which recognizes all the Mena isoforms and do not crossreact with other members of ENAVASP family. Indirect streptavidinbiotin-peroxidase system was applied in formalin-fixed, paraffin-embedded sections. For antigen unmasking, the deparaffinized and rehydrated sections were pretreated in a thermostatic bath at $96^{\circ} \mathrm{C}$ for $30 \mathrm{~min}$ in $10 \mathrm{mM}$ citrat buffer, $\mathrm{pH} 6$. It was followed by endogenous peroxidase blocking and incubation with pri- 
mary and secondary antibody (LabVision, Kalamazoo, MI, USA) at room temperature. HRP Polymer detection kit (Ultravision LP Large Volume, LabVision) served as visualisation system. The development was performed with substrate-chromogen solution $3,3^{\prime}$ Diamino Dihidrochlorid Benzidine (DAB) for 3-5 min. The nuclei were counterstained with Mayer`s Hematoxylin. We should mention that for each staining batch avidin-biotin blocking of non-specific background staining was performed in order to reduce the non-specific background staining. ${ }^{11,12}$

The Mena immunostaining was scored in the cytoplasm of tumor cells according to the following criteria: score 0, no staining; score $1+$, weak diffuse cytoplasmic staining in $<10 \%$ of cells; score $2+$, moderate cytoplasmic staining in $10 \%$ to $70 \%$ of cells a; score $3+$, strong cytoplasmic staining in $>70 \%$ of the cells, with or without juxtamembrane reinforce. Smooth muscle cells were used as an internal positive control. ${ }^{13}$ For external control we used human cerebellum as positive and spleen as negative control. ${ }^{14,15}$

The digital pictures were realized with Nikon $800 \mathrm{E}$ microscope and were processed using Image J (NIH) software. Mena intensity was statistically correlated with following clinicopathological parameters: patients sex and age, tumor type, tumor stage, grade of malignancy, lymph node metastases, rate of recurrence and angiolymphatic invasion. For statistical analysis, we used the statistics program GraphPad InStat 3 . We used the $t$-test, $\chi^{2}$-test and the contingency tables, Fischer's test and One way Anova test. A P value $<0.05$, with a $95 \%$ confidence interval, was considered significant.

Table 1. Distribution of patients in the study.

\begin{tabular}{lc} 
Type of tissue & $\begin{array}{c}\text { No. of } \\
\text { patients }\end{array}$ \\
Normal salivary glands & 10 \\
Benign tumors & 20 \\
Pleomorphic adenoma & 10 \\
Warthin's tumor & 10 \\
\hline Malignant tumors & 35 \\
Salivary duct carcinoma & 5 \\
Carcinoma in pleomorphic adenoma & 5 \\
Acinic cell carcinoma & 5 \\
Squamous cell carcinoma & 10 \\
Mucoepidermoid carcinoma & 5 \\
Lymphoma & 5 \\
\hline
\end{tabular}
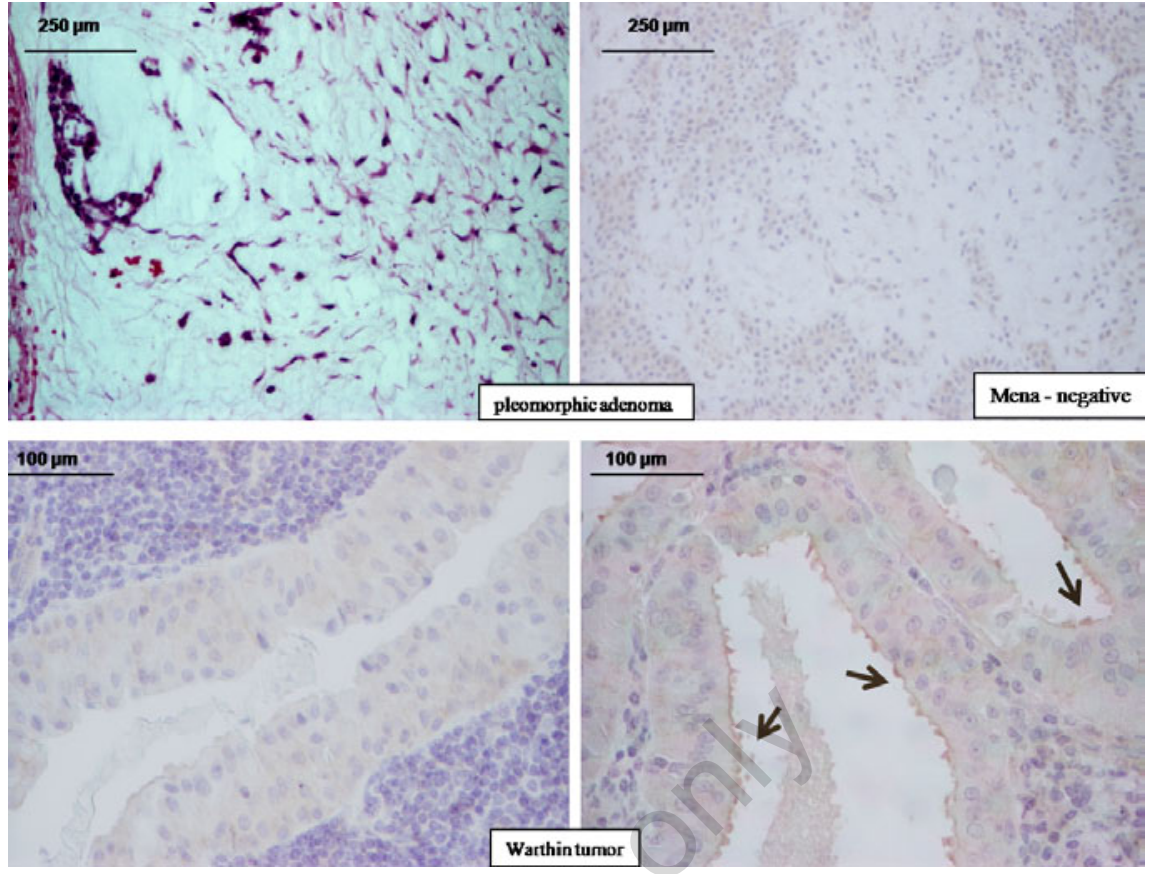

Figure 1. Lack of Mena expression in benign tumors of salivary glands. The arrows indicate extracellular apical positivity.

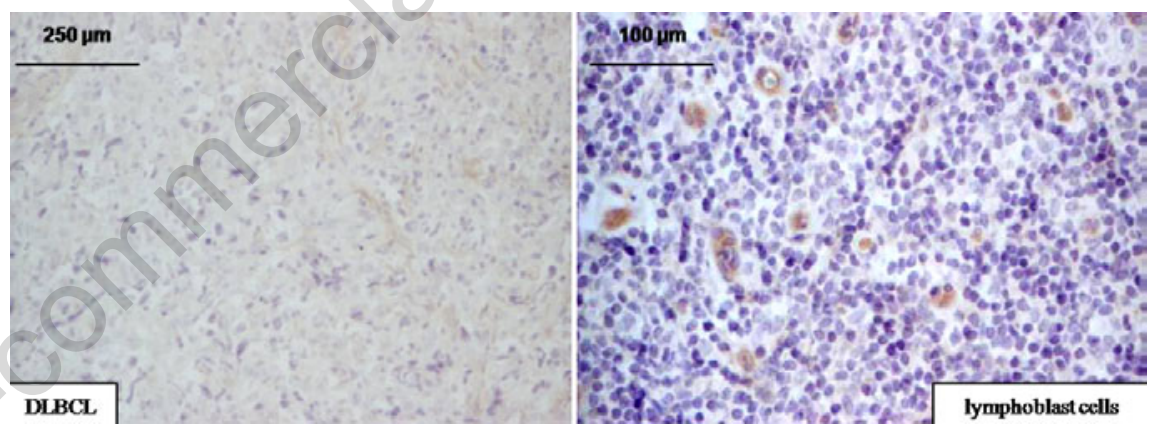

Figure 2. Lack of Mena expression in diffuse large B-cell lymphomas (DLBCL), with positivity of lymphoblast cells.

Table 2. Clinical parameters of patients.

\begin{tabular}{lcc} 
Type of tissue & $\begin{array}{c}\text { Age } \\
\text { median/interquartile } \\
\text { range (years) }\end{array}$ & $\begin{array}{c}\text { Male/female } \\
\text { (ratio) }\end{array}$ \\
Normal salivary glands & $55.62(46-70)$ & $1 / 1$ \\
Benign tumors & $60.12(44-76)$ & $4 / 1$ \\
\hline Pleomorphic adenoma & $51.33(44-64)$ & $1 / 3$ \\
Warthin's tumor & $73.01(70-76)$ & $10 / 0$ \\
\hline Malignant tumors & $61.36(35-85)$ & $1 / 1$ \\
Salivary duct carcinoma & $71.23(70-73)$ & $2 / 1$ \\
\hline Carcinoma in pleomorphic adenoma & $62.34(55-65)$ & $1 / 1$ \\
Acinic cell carcinoma & $51.45(37-65)$ & $1 / 3$ \\
\hline Squamous cell carcinoma & $74.66(62-85)$ & $3 / 1$ \\
Mucoepidermoid carcinoma & $46.52(35-63)$ & $1 / 3$ \\
\hline Lymphoma & $54.66(41-62)$ & $1 / 2$
\end{tabular}




\section{Results}

\section{Patients' characteristics}

The demographic distribution of patients is presented in Table 2. We found a female predominance in pleomorphic adenomas $(\mathrm{P}=0.03)$, acinic cell carcinomas $(\mathrm{P}=0.04)$ and mucoepidermoid carcinomas $(\mathrm{P}=0.01)$. In case of malignant tumors, the median age was 61.36 years (range between $35-85$ years). All Wharthin tumors were diagnosed in males older than 70 years. No statistical differences between age of patients with benign or malignant tumors were observed $(\mathrm{P}=0.65)$. Only one patient with carcinoma in pleomorphic adenoma presented recurrences, one year after surgical interventions. All patients survived one year after surgical intervention.

\section{Particularities of Mena staining}

As already mentioned, the quantification of Mena intensity was performed in the cytoplasm of the tumor cells, independently by the membranar aspect.

No differences between sex or age of patients and Mena intensity was observed in both benign and malignant tumors of $\mathrm{SG}$ $(\mathrm{P}=0.0003)$. In normal salivary gland tissue, Mena was not detectable. All pleomorphic adenomas were also Mena negative (Figure 1). Regarding Warthin's tumors, the tumor cells were Mena negative but in one case a weak positivity was observed extracellular, on the surface of the apical membrane (Figure 1). This case was also considered negative and the strange positivity cannot be explained at the moment. It may be a positivity of the tumor secretion but future studies should elucidate this aspect. Regarding the intensity of Mena staining in diffuse large B-cell lymphomas, four out of five lymphomas were Mena negative. However, in one case lymphoblastic cells were Mena positive (Figure 2).

We observed that Mena staining intensity was $1+$ in two cases and 2+ in three cases of acinic cell carcinoma. Furthermore, in all salivary duct carcinomas and carcinomas in pleomorphic adenomas the intensity of Mena staining was $3+$ regardless whether the cases were with or without relapses (Figure 3, Table 3). In squamous cell carcinomas and mucoepidermoid carcinomas we observed a positive correlation between tumor grade and intensity of Mena staining. In low grade squamous cell carcinomas the intensity of Mena staining was $2+$ and in high grade squamous cell carcinomas Mena intensity was 3+ (Figure 4). In mucoepidermoid carcinomas, no or weak positivity was revealed by low- and intermediategrade carcinomas but the strong intensity $(3+)$ was observed in high-grade types (Figure

\section{5 , Table 3 )}

In case of salivary duct carcinomas, independently by the tumor type, the mena intensity was not correlated with other parameters than tumor grade and vascular invasion, being $2+$ or $3+$ in all high-grade carcinomas and in cases with vascular invasion. In acinic cell carcinomas, for example, although it is a lowgrade tumor, all 3 cases with $2+$ intensity pre- sented vascular invasion but no invasion was identified in the two cases with 1+ intensity.

No correlation have been observed between Mena intensity and other clinicopathologic parameters as: patients`sex and age, tumor stage or lymph node metastases. Although the Mena intensity was increased in the invasion front, the small number of cases and minimal differences between intensity inside of tumor

Table 3. Mena protein expression in salivary gland carcinomas correlated with grade of malignancy.

\begin{tabular}{lcccc} 
No. of cases & \multicolumn{3}{c}{ Mena score } \\
& 0 & $1+$ & $2+$ & $3+$ \\
Salivary duct carcinoma: 5 & - & - & - & 5 \\
Carcinoma in pleomorphic adenoma: 5 & - & - & - & 5 \\
\hline $\begin{array}{l}\text { Acinic cell carcinoma: } 5 \\
\text { Squamous cell carcinoma: } 10\end{array}$ & - & 2 & 3 & - \\
$\quad$ low-grade: 4 & - & - & 4 & - \\
high-grade: 6 & - & - & - & 6 \\
\hline $\begin{array}{l}\text { Mucoepidermoid carcinoma: } 5 \\
\text { low-grade: 1 }\end{array}$ & 1 & - & - & - \\
intermediate-grade: 2 & 1 & 1 & - & - \\
high-grade: 2 & - & - & - & 2 \\
\hline
\end{tabular}
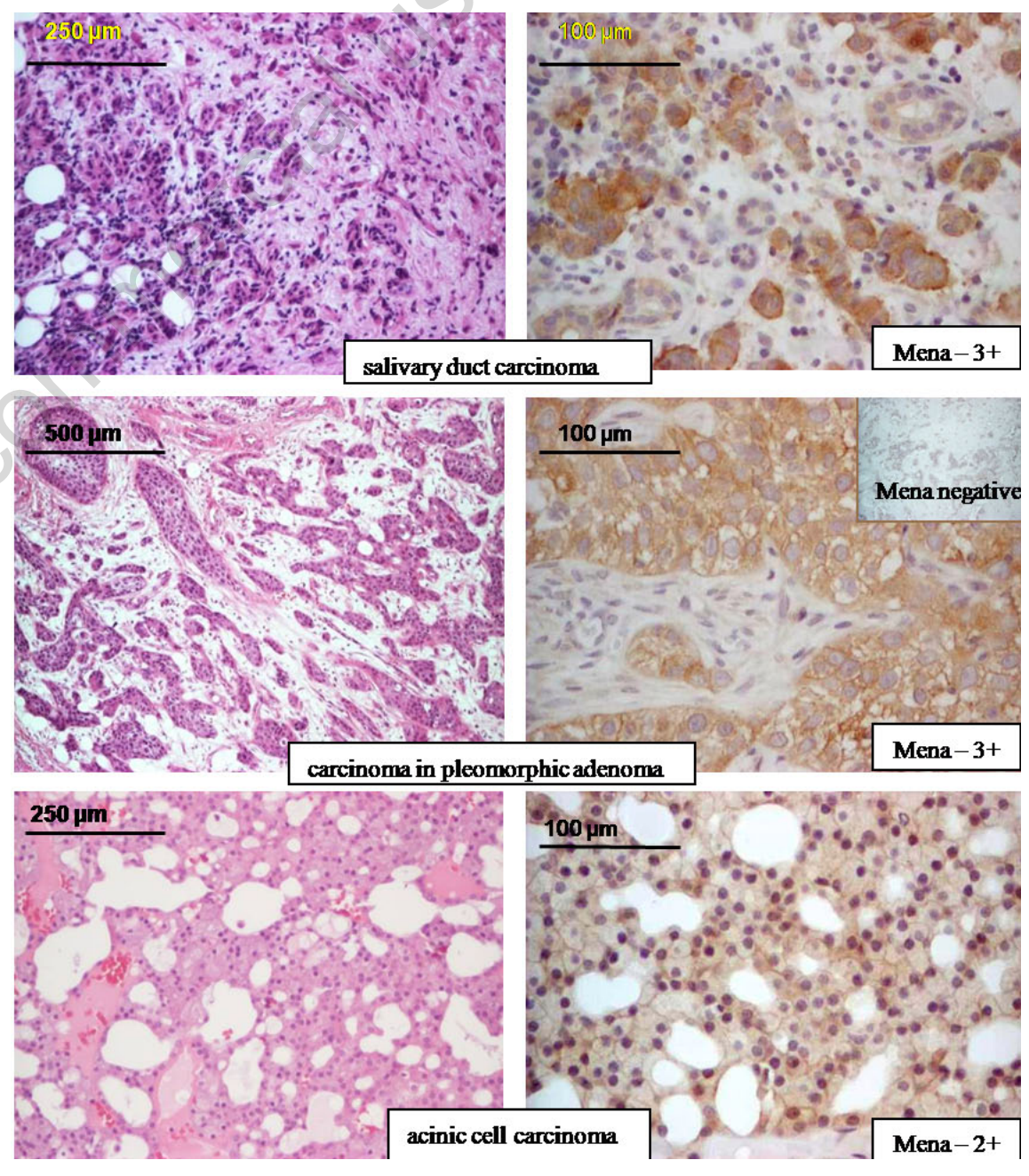

Figure 3. Mena protein positivity in some salivary carcinomas. In the carcinoma developed in pleomorphic adenoma, Mena staining lack in the areas of adenoma. 
and invasion front do not allowed us to emite a pertinent sentence about this aspect.

In some cases, we observed that some endothelial cells in the peritumoral vessels were Mena positive (Figure 6).

\section{Discussion}

Malignant tumors of salivary glands (SG) have a low incidence and can appear de novo or through malignant transformation of benign tumors. However, salivary duct carcinomas, invasive carcinomas ex pleomorphic adenomas and also high grade squamous carcinomas are extremely agressive tumors, with high rate of recurrences and distant metastasis. ${ }^{4}$ Pleomorphic adenomas recur in $3.4 \%$ of cases in 5 years and $6.8 \%$ in 10 years. Furthermore, the risk for malignant transformation is higher in young patients. ${ }^{16}$ Variable outcome in individual cases was observed. To predict patients' outcome different grading systems were proposed but they are still under debate, especially for mucoepidermoid carcinoma, adenoid cystic carcinoma and malignant mixed tumors. ${ }^{5}$

Our study suggests that the actin-binding protein Mena, a member of Ena/VASP family may play a role in tumorigenesis of SG. We observed a positive correlation between Mena expression levels and tumor grade indicating that Mena might serve as a biomarker, especially in those cases in which criteria for grading system are not very well defined. Its intensity was also positively correlated with the grade of cervical intraepithelial neoplasia and risk of metastasis in breast and pancreatic tumors. ${ }^{8,9,13}$ It was shown previously that in colon lesions Mena marked only some adenomas with dysplasia and all carcinomas, further supporting the idea that Mena expression levels could be used as a prognostic marker. ${ }^{1}$

In salivary glands, lack of Mena expression in normal tissue and benign tumors and its increase in intensity in carcinomas also reported for other epithelial neoplasms suggests that reorganization of the actin cytoskeleton is activated during malignant transformation..$^{810}$ In tumors of several organs Mena staining localizes in the cytoplasma of tumor cells. ${ }^{8,10,13}$ Interestingly, we observed that in malignant salivary tumors both cytoplasma and the plasma membrane, an important intracellular site of Mena function, were labelled.

Lack of positivity in benign tumors and low or moderate Mena intensity $(1+, 2+)$ in acinic cell carcinomas, low grade squamous carcinomas and low- or intermediate-grade mucoepidermoid carcinoma, which are considered to have a better prognosis, suggest that Mena could be a prognostic factor in salivary tumors.
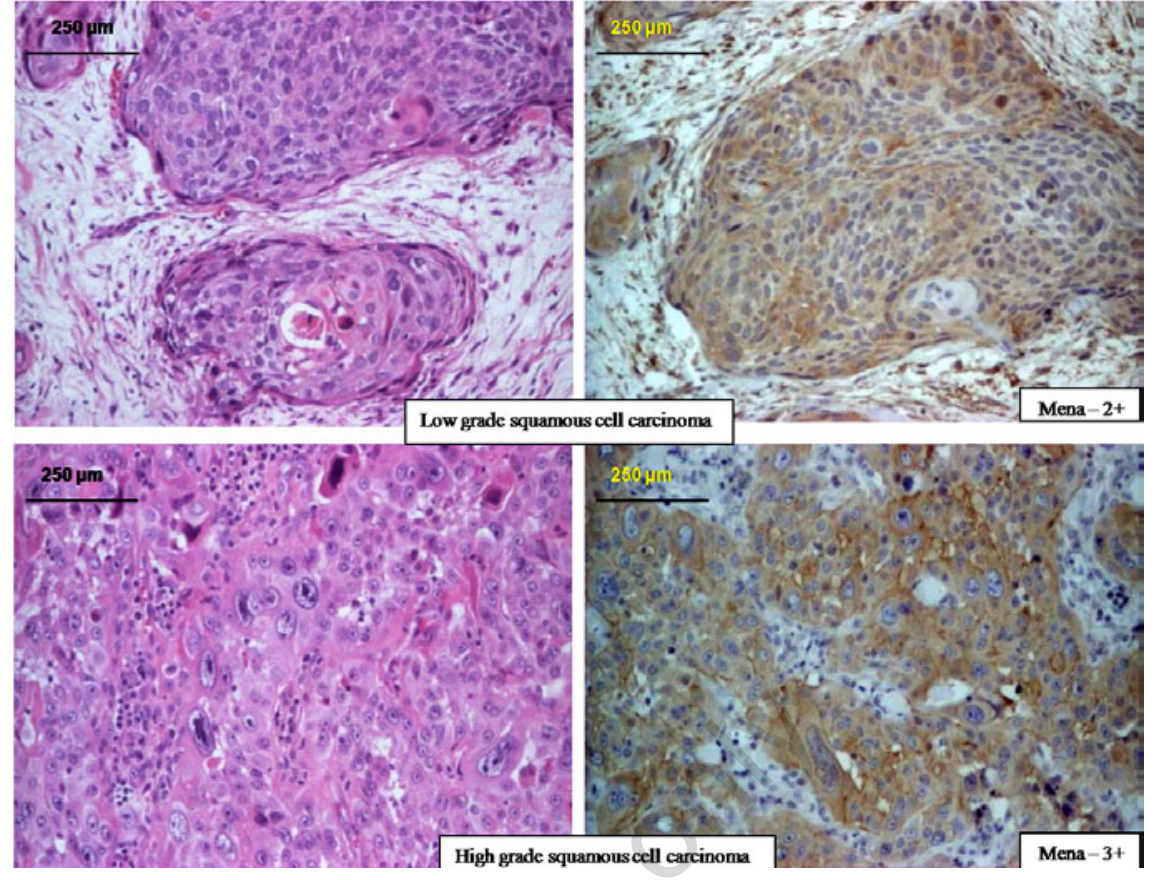

Figure 4. High intensity of Mena protein in high grade squamous cell carcinoma in contrast with intermediar positivity in low grade variant.

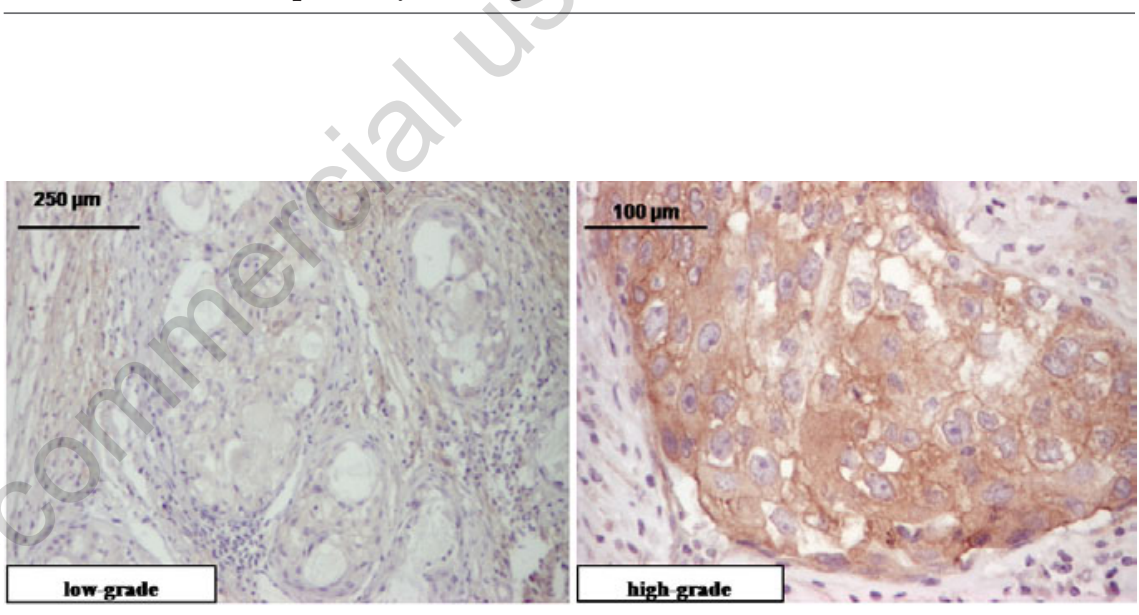

Figure 5. High intensity of Mena protein in high grade mucoepidermoid carcinoma in contrast with lack of expression in low grade variant.

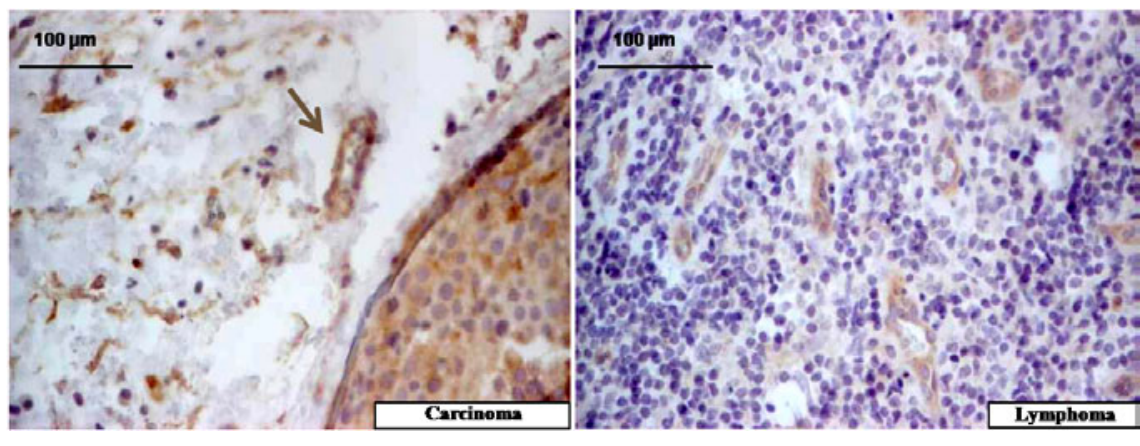

Figure 6. Endothelial cells marked by Mena in salivary squamous cell carcinoma carcinoma and diffuse Large B-cell lymphoma. 
Its intensity may also indicate the probability of presence or absence of vascular invasion. Based on previous statement, carcinomas in pleomorphic adenomas, salivary duct carcinomas and high grade squamous cell carcinomas remain agressive salivary tumors. We should mention again that Mena could help the pathologist in correct staging of mucoepidermoid carcinoma and proper predicting of prognosis.

Our suggestions are in accordance with other recent studies which revealed that multiphoton-based intravital imaging of Mena protein has demonstrated that it may be used to develop prognostic tests which can be useful for patients with different malignancies. ${ }^{17-19}$ This sentence is based on observation that an alternative splicing of Mena produces two protein isoforms with distinct finctions: Mena ${ }^{\mathrm{INV}}$ (previously called Mena ${ }^{+++}$) and Menalla, ${ }^{17}$ both of them being part of a marker of metastatic risk called Tumor Micro-Environment of Metastasis (TMEM) but having opposite effects. ${ }^{18}$ One hand, Mena ${ }^{\mathrm{INV}}$ is present only in invasive tumor cells and is not a component of other members of ENANASP family. In case of breast cancer, it can promote the discohesivity of tumor cells, increases their motility, transendothelial migration and intravastion, favorizing the metastatic process. ${ }^{18,19}$ On the other hand, Mena1la seems to be specifical for primary epithelial cancer cells but is not counterpart of mesenchymal cells or invasive tumor cells. ${ }^{17}$ It contribute to supression of the paracrine-mediated invasion and intravasation of the breast cancer cells. ${ }^{19}$ These studies proved that the steps of metastasation in case of breast cancer depend on the predominated Mena isoform. . $^{18,19}$

At the moment, the immunohistochemical methods can identify the combined form of Mena. In the future, new antibodies with the splicing variant of Mena could be useful to predict prognosis but also to develop new drugs which can inhibite MenaINV and prevent metastatic disease in case of breast cancer but also in other malignant tumors.

The lack of Mena expression in lymphomas suggests that the actin filaments are not implied in genesis of lymphomas but Mena positivity in lymphoblast cells proves that actin reorganization or phosphorylation could influences outcome of lymphomas. No studies about Mena aspects in lymphomas were published yet.

Furthermore, we observed Mena expression in some of the stroma endothelial cells. Therefore, it is tempting to speculate that Mena might play a role in tumor angiogenesis. Previous studies revealed that in the endothelium, the Ena/VASP family functions during sealing of cell-cell contacts and hence regulation of endothelial permeability. ${ }^{20-23}$ Ena/VASP proteins have also been implicated in endothelial reorganization during capillary morphogenesis. ${ }^{24}$ In support of a role for Ena/NASP proteins in tumor angiogenesis we observed a significant correlation between Mena intensity and presence of vascular invasion and also with microvascular density in colorectal carcinoma. ${ }^{10}$

Further studies on a higher number of patients with benign and malignant salivary tumors, which include many categories of tumors, will be required to further evaluate the suitability of Ena/NASP proteins as prognostic or predictive biomarkers.

\section{References}

1. Speight PM, Barrett AW. Salivary gland tumours. Oral Dis 2002;8:229-40.

2. Boukheris H, Curtis RE, Land CE, Dores GM. Incidence of carcinoma of the major salivary glands according to the World Health organization (WHO) Classification, 1992-2006: a population-based study in the United States. Cancer Epidemiol Biomarkers Prev 2009;18:2899-906.

3. Iwafuchi H, Mori N, Takahashi T, Yatabe Y. Phenotypic composition of salivary gland tumors: an application of principle component analysis to tissue microarray data. Mod Pathol 2004;17:803-10.

4. American Joint Committee on Cancer. Major Salivary Glands. In: SB Edge, DR Byrd, CC Compton, AG Fritz, FL Greene, A Trotti (eds.) AJCC Cancer Staging Manual, 7th ed. 2010, Springer, New York, USA, pp. 103-7.

5. Tawfik 0, Namiq A. Tumors of the salivary glands. In: I Damjanov, F Fan (eds.) Cancer Grading Manual. 2007, Springer, New York, USA, pp 13-8.

6. Olson MF, Sahai E. The actin cytoskeleton in cancer cell motility. Clin Exp Metastasis 2009;26:273-87.

7. Krause M, Dent EW, Bear JE, Loureiro JJ, Gertler FB. Ena/NASP proteins: regulators of the actin cytoskeleton and cell migration. Annu Rev Cell Dev Biol 2003;19:54164.

8. Di Modugno F, Demonte L, Balsamo M, Bronzi G, Nicotra MR, Alessio M, et al. Mollecular cloning of hMena (ENAH) and its splice variant hMena+11a: epidermal growth factor increases their expression and stimulates hMena+11a phosphorylation in breast cancer cell lines. Cancer Res 2007;67:2657-65.

9. Pino MS, Balsamo M, Di Modugno F, Mottolese M, Alessio M, Melucci E, et al. Human Mena+11a isoforms serves as a marker of epithelial phenotype and sensi- tivity to epidermal growth factor receptor inhibition human pancreatic cell lines. Clin Cancer Res 2008;14:4943-50.

10. Gurzu S, Jung I, Prantner I, Pavai Z, Mezei T. The expression of cytoskeleton regulatory protein Mena in colorectal lesions. Rom J Morphol Embryol 2008;49:45-9.

11. Lu CS, Kashima K, Daa T, Yokoyama S, Yanagisawa S, Nakayama I. Immunohistochemical study of the distribution of endogenous biotin and biotin-binding enzymes in ductal structures of salivary gland tumours. J Oral Pathol Med 2000; 29:445-51.

12. Kim SH, Jung KC, Shin YK, Lee KM, Park YS, Choi YL, et al. The enhanced reactivity of endogenous biotin-like molecules by antigen retrieval procedures and signal amplification with tyramine. Histochem J 2002;34:97-103.

13. Gurzu S, Jung I, Prantner I, Chira L, Ember I. The immunohistochemical aspects of protein Mena in cervical lesions. Rom J Morphol Embryol 2009;50:213-6.

14. Gambaryan S, Hauser W, Kobsar A, Glazova M, Walter U. Distribution, cellular localization and postnatal development of VASP and Mena expression in mouse tissues. Histochem Cell Biol 2001;116:535-43.

15. Toyoda A, Kawana H, Azuhata K, Yu J, Omata A, Kishi H, et al. Aberrant expression of human ortholog of mammalian enabled (hMena) in human colorectal carcinomas: Implications for its role in tumor progression. Int J Oncol 2009;34:53-60.

16. Laskawi R, Schott T, Schroder M. Recurent pleomorphic adenomas of the parotid gland: clinical evaluation and long-term folow-up. Br J Oral Maxilofac Surg 1998; 36:48-51.

17. Gertler F, Condeelis J. Metastasis: tumor cells becoming MENAcing. Trends Cell Biol 2011;21:81-90.

18. Roussos ET, Goswami S, Balsamo M, Wang Y, Stobezki R, Adler E, et al. Mena invasive (MenaINV) and Menalla isoforms play distinct roles in breast cancer cell cohesion and association with TMEM. Clin Exp Metastasis 2011;28:515-27.

19. Roussos ET, Balsamo M, Alfrod SK, Wyckoff JB, Gligorijevic B, Wang Y, et al. Mena invasive (MenaINV) promotes multicellular streaming motility and transendothelial migration in a mouse model of breast cancer. J Cell Sci 2011;124:2120-31.

20. Furman C, Sieminski AL, Kwiatkowski AV, Rubinson DA, Vasile E, Bronson RT, et al. Ena/VASP is required for endotelial barrier function in vivo. J Cell Biol 2007;179:76175.

21. Benz PM, Blume C, Moebius J, Oschatz C, Schuh K, Sickmann A, et al. Cytoskeleton 
assembly at endotelial cell-cell contacts is regulated by alphaII-spectrin-VASP complexes. J Cell Biol 2008;180:205-19.

22. Rentsendorj 0, Mirzapoiazova T, Adyshev D, Servinsky LE, Renne T, Verin AD, et al. Role of vasodilator-stimulated phosphoprotein in cGMP-mediated protection of human pulmonary artery endotelial barri- er function. Am J Physiol Lung Cell Mol Physiol 2008;294:L686-97.

23. Schlegel N, Burger S, Golenhofen N, Walter U, Drenckhahn D, Waschke J. The role of VASP in regulation of cAMP- and Rac 1-mediated endotelial barrier stabilization. Am J Physiol Cell Physiol 2008; 294:C178-88.
24. Salazar R, Bell SE, Davis GE. Coordinate induction of the actin cytoskeletal regulatory proteins gelsolin, vasodilator-stimulated phosphoprotein, and profilin during capillary morphogenesis in vitro. Exp Cell Res 1999;249:22-32. 